\title{
Understanding Model-Based Probable Maximum Precipitation Estimation as a Function of Location and Season from Atmospheric Reanalysis $\mathscr{O}$
}

\author{
XiaOdong Chen AND FAISAl Hossain \\ Department of Civil and Environmental Engineering, University of Washington, Seattle, Washington
}

(Manuscript received 5 September 2017, in final form 16 January 2018)

\begin{abstract}
Extreme precipitation events bring huge societal and economic loss around the world every year, and they have undergone spatially heterogeneous changes in the past half-century. They are fundamental to probable maximum precipitation (PMP) estimation in engineering practice, making it important to understand how extreme storm magnitudes are related to key meteorological conditions. However, there is currently a lack of information that can potentially inform the engineering profession on the controlling factors for PMP estimation. In this study, the authors present a statistical analysis of the relationship between extreme 3-day precipitation and atmospheric instability, moisture availability, and large-scale convergence over the continental United States (CONUS). The analysis is conducted using the North America Regional Reanalysis (NARR) and ECMWF ERA-Interim reanalysis data and a high-resolution regional climate simulation. While extreme 3-day precipitation events across the CONUS are mostly related to vertical velocity and moisture availability, those in the southwestern U.S. mountain regions are also controlled by atmospheric instability. Vertical velocity and relative humidity have domainwide impacts, while no significant relationship is found between extreme precipitation and air temperature. Such patterns are stable over different seasons and extreme precipitation events of various durations between 1 and 3 days. These analyses can directly help in configuring the numerical models for PMP estimation at a given location for a given storm.
\end{abstract}

\section{Introduction}

Extreme rainstorms are events that rarely happen and whose magnitudes are far beyond the average climatological statistics. They are responsible for a large fraction of flooding and landslides and bring huge societal and economic losses every year (Evans et al. 2000; Casagli et al. 2006; Cong et al. 2006). The historical changes in extreme rainstorms are often attributed to global warming (Min et al. 2011), but studies also show that the historical trends of extreme precipitation vary as a function of duration (from hourly to daily; Kunkel et al. 2013a; Prein et al. 2017). This difference suggests that the relationship between air temperature and precipitation is not simple. Therefore, a better understanding of the relationship between various atmospheric conditions and precipitation is a necessity.

\footnotetext{
Supplemental information related to this paper is available at the Journals Online website: https://doi.org/10.1175/JHM-D-170170.s1.

Corresponding author: Faisal Hossain, fhossain@uw.edu
}

Extreme rainstorms are also the cornerstone of the engineering design community for water management. Large water management infrastructures have been built to last from tens to hundreds of years using probable maximum precipitation (PMP) as a key criterion. PMP is now widely used in the design of these infrastructures all around the world. It is defined as the theoretical greatest depth of precipitation for a given duration that is physically possible over a particular drainage area (Huschke 1959). During the past several decades, PMP has been mostly estimated through moisture maximization of extreme rainstorm observations as $\mathrm{PMP}=P \times \mathrm{PW}_{m} / \mathrm{PW}_{o}$ (World Meteorological Organization 1986; Schreiner and Riedel 1978; Kunkel et al. 2013b). Here $P$ is the observed rainfall amount, $\mathrm{PW}_{o}$ is the observed precipitable water in the same event, and $\mathrm{PW}_{m}$ is the observed maximum precipitable water over a certain time duration (such as $12 \mathrm{~h}$ ).

Although moisture maximization is one of the most widely used techniques for PMP estimation, various studies have investigated the underlying deficiencies in this approach. A consensus that emerges from those studies is that a numerical model-based method is expected to be physically superior for the estimation of 
PMP (Abbs 1999; Tan 2010; Ohara et al. 2011; Ishida et al. 2015; Stratz and Hossain 2014; Chen and Hossain 2016). The numerical approach is based on the physical maximization of a phenomenon relevant to the historical storm reconstruction. A recent study by Chen and Hossain (2016) has shown that it is now possible to reconstruct the infrastructure-relevant extreme rainstorms of the continental United States (CONUS) after 1948 with acceptable accuracy. However, up to now, there is no consensus on how to physically "maximize" the historical storms for PMP estimation using numerical models.

The ways to maximize storms as reported in literature can be classified into these categories: 1) the disturbance of air moisture through changing air temperature/relative humidity and keeping the atmospheric columns throughout the simulation domain fully moist during the storm events (Tan 2010; Ohara et al. 2011), 2) the disturbance of moisture flux through changing wind speed or wind fields (Ishida et al. 2015), and 3) the combination of the worst historical environmental conditions (Tan 2010). One particular issue that makes such techniques appear ad hoc is that there has been no comprehensive study to date that investigates the key atmospheric conditions that affect extreme storms (e.g., moisture availability, atmospheric instability, largescale convergence). Thus, the engineering community is left without a rational guideline on the use of numerical models for PMP estimation. The information on how extreme historical rainstorms are controlled by environmental conditions is now timely as the engineering community debates and reevaluates the future risk of water management infrastructures (Chen and Hossain 2016).

There have been various studies on the cause of extreme storms, mostly on selected events. For example, a series of studies examined a heavy rainfall event in Mumbai, India, and identified the synoptic-scale weather systems and land surface feedback as contributors to this epic event (Kumar et al. 2008; Chang et al. 2009; Rama Rao et al. 2007; Vaidya and Kulkarni 2007). Similarly, the record-breaking Nashville, Tennessee, storm on May 2010 was investigated in Moore et al. (2012) and Durkee et al. (2012), and it was concluded that the storm was a result of the interaction between the North Atlantic Oscillation, an atmospheric river, and strong land surface feedback. These studies now provide a platform for systematic analysis that can be used as a "design monograph" or guide that engineers are so inclined to apply in practice. Some studies have also been done on the general relationship between extreme storms and environmental factors, but most of them only checked the relationship at the hourly scale or for selected events (Hardwick Jones et al. 2010; Mishra et al. 2012; Hand et al. 2004; Ducrocq et al. 2014).

Other studies approached this problem by systematically checking certain environmental factors (Davies et al. 2013; Lepore et al. 2015). For example, Davies et al. (2013) identified the significant roles of moisture convergence in tropical rainfall events. Loriaux et al. (2016) found that atmospheric instability, moisture availability, and horizontal wind convergence are all positively related to the hourly peak rainfall intensity in the Netherlands. The rainfall events were treated in a single analysis, and no spatial patterns were analyzed. Some exceptions, such as the study by Lepore et al. (2015) that divided the eastern United States into four subregions, reveal the geographic patterns at a quite coarse scale, and the results are not spatially fine enough to inform the engineering design practice for water management infrastructure. These studies also indicate the usefulness of atmospheric reanalysis products in such analyses. More localized analysis at small subregions is required, especially for engineering practices such as PMP estimation.

To address this need, some studies often correlate precipitation with various environmental conditions. Other studies further quantify these correlations as regressions (Lepore et al. 2015). However, by this approach it is difficult to account for most of the time lags between extreme rainfall intensity and extreme environmental conditions. To avoid the lag issue, our study analyzes the environmental conditions in 72-h durations, which is also a general standard design period for large water management infrastructures. Also, this correlation/regression approach inexplicitly assumes a fixed relationship between precipitation and environmental factors. For example, Lepore et al. (2015) assumed a linear relationship between precipitation and atmospheric instability. This may introduce extra uncertainties in the regression results. To overcome this, in this study we look at a wide range of atmospheric conditions in the frequency space and make connections between these percentiles by asking the following: When an extreme storm happens, what are the meteorological factors that appear dominant in the same duration?

In this study, we examine the extreme precipitation events archived in the North American Regional Reanalysis (NARR) and European Centre for MediumRange Weather Forecasts (ECMWF) interim reanalysis (ERA-Interim). The use of two reanalysis products helps us to make conclusions that are robust and not subjective to the choice of the product. By extracting the extreme precipitation events across the CONUS and 
investigating the atmospheric conditions, we answer the following three PMP-relevant questions:

1) How has extreme 3-day precipitation changed in the past half-century?

2) What is the relationship between atmospheric conditions and the extreme rainstorms in the CONUS during 1979-2015 as revealed by reanalysis?

3) Does the impact of these atmospheric factors show any geographically consistent patterns?

By answering these questions, we find the connections between extreme precipitation and meteorological factors and use the climatic trends of these factors to explain the trend of extreme precipitation. Also, this would reveal how extreme precipitation is likely to behave under the change of these factors, so that simulated "maximization" is rationalized in numerical models. The paper is organized as follows. In section 2, we introduce the NARR and ERA-Interim data used in this study, as well as the diagnosis variables employed. In section 3, we show the relationship between extreme precipitation amounts and various environmental factors during 1979-2015, as well as the geographic distribution of the dominant controls on extreme rainstorms. Further discussions of the results are presented in section 4. A summary and conclusions are presented in section 5 .

\section{Data and methods}

\section{a. Reanalysis, simulation, and observation data}

The NARR project is produced by the National Centers for Environmental Prediction (NCEP). It reconstructs the weather conditions of North America since 1979 (Mesinger et al. 2006). This reanalysis is done by assimilating observations from various sources on air temperature, moisture, pressure, and wind fields. It also utilizes the surface observations of precipitation, which ensures a physically consistent quality in the reconstruction of precipitation. Studies have shown that NARR has an improved representation of precipitation climatological patterns when compared with previous reanalysis products, especially within the CONUS domain (Bukovsky and Karoly 2007; Nigam and RuizBarradas 2006). For this reason, NARR has been used in the investigations of extreme weather events (Neiman et al. 2011; Wang et al. 2016).

ERA-Interim is the second-generation global reanalysis product from ECMWF (Dee et al. 2011). It is produced using a 4D data assimilation system and benefits from various sources of observations including satellite data. ERA-Interim has been used in various studies on historical extreme weather events, including extreme precipitation (Pfahl and Wernli 2012; Guan et al. 2010; Seneviratne et al. 2014). It has also been used as a historical reference to evaluate the extreme weather in climate models (Kharin et al. 2013).

Some basic information about these two datasets is provided in Table 1. In this study, we took the data of 1979-2015 (37 years) and extracted the top fifty 72-h precipitation events in every grid of the two datasets. At every model grid, we calculated the 72 -h precipitation (hereafter called MP72) time series and identified the 50 events with the greatest 72 -h precipitation. To check the quality of the reconstructed precipitation climatology, we compared the maximum 72-h precipitation (i.e., the top event) during 1979-2011 against gridded observations (Livneh et al. 2013), as shown in Fig. 1. The Livneh gridded daily precipitation data are generated using the gauge observations across the United States since 1915, and it is one of the few long-term gridded datasets available. With a higher spatial resolution, NARR better captures the impact of land topography on the atmosphere. This results in higher simulated precipitation from NARR on the West Coast and over the southeastern United States, which is closer to the Livneh data. Figure 1d shows the correlation of maximum 72-h precipitation between the two reanalysis products with the Livneh data. NARR has a slightly better performance, though in general the two reanalysis products show the spatial variation reasonably well. In our analysis, we focus on the NARR data and take the ERA-Interim as a validation.

\section{b. Diagnostic atmospheric variables}

Based on previous studies (Davies et al. 2013; Lepore et al. 2015; Loriaux et al. 2016), we first focus on the relationship between extreme precipitation and the following meteorological factors: atmospheric instability, moisture availability, and moisture convergence. These are assumed to be major factors related to extreme precipitation. Therefore, we investigate the roles of the following atmospheric conditions in the initiation and evolution of precipitation: convective available potential energy (CAPE), precipitable water $(\mathrm{PW})$, and vertical wind velocity (wind). CAPE is defined as the energy that a parcel of air would have if it were vertically lifted a certain distance in the atmosphere. In this study, we used surface-based CAPE, and it is calculated using Eq. (1), where $\mathrm{Z} 1$ is the land surface, $\mathrm{Z} 2$ is the equilibrium level, $T_{v, p}$ is the virtual temperature of the parcel, $T_{v, e}$ is the virtual temperature of the environment, and $g$ is the gravitational constant. CAPE is widely used to indicate atmospheric instability, and it is useful in severe weather prediction (Brooks et al. 2003; Markowski et al. 2002). In general, positive 
TABLE 1. Datasets used in this study.

\begin{tabular}{lccl}
\hline \multicolumn{1}{c}{ Dataset } & Range & Spatial resolution & \multicolumn{1}{c}{ Temporal resolution } \\
\hline NARR & 1979 to present & $32 \mathrm{~km} / 29$ levels & $3 \mathrm{~h}$ \\
ERA-Interim & 1979 to present & $0.75^{\circ} / 60$ levels & $12 \mathrm{~h}$ (precipitation, CAPE); 6 h (PW, wind, RH, Tair) \\
\hline
\end{tabular}

CAPE indicates an unstable condition, and the higher the CAPE value, the more unstable the atmosphere is:

$$
\mathrm{CAPE}=\int_{\mathrm{Z} 1}^{\mathrm{Z} 2} g \frac{T_{v, p}-T_{v, e}}{T_{v, e}} d z
$$

Precipitable water is the vertical integration of moisture in the air column. It is calculated using Eq. (2), where $x$ is the mixing ratio at the pressure level, $\mathrm{p} 1$ is the surface pressure, and $\mathrm{p} 2$ is the uppermost-level pressure $(100 \mathrm{mb}$ in NARR and $1 \mathrm{mb}$ in ERA-Interim; $1 \mathrm{mb}=$ $1 \mathrm{hPa})$. PW indicates the moisture availability for the rainstorm, and in heavy rainstorm events, moisture that is several times that of the PW can be depleted:

$$
\mathrm{PW}=\frac{1}{\rho g} \int_{\mathrm{p} 1}^{\mathrm{p} 2} x d p .
$$

(a) max 3-day P: Livneh

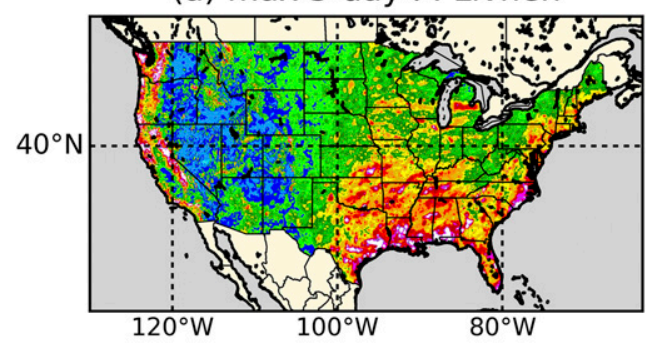

(c) max 3-day P: ERA-Interim

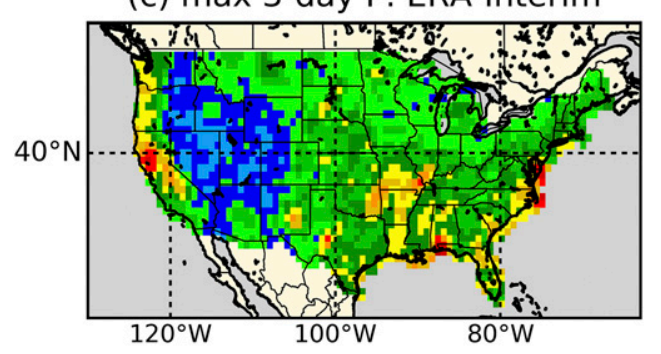

Vertical wind is directly taken from reanalysis fields, presented as the velocity between pressure levels. From the mass balance perspective, the strength of vertical velocity is also an approximation of the large-scale horizontal convergence (LSC). Our analysis suggests that the greatest vertical velocity happens at $700 \mathrm{mb}$ in the MP72 duration. This is in agreement with earlier studies of midlatitude storms (Loriaux et al. 2016), and in the following analysis we will analyze the vertical velocity at $700 \mathrm{mb}$, as it is most related to precipitation processes.

CAPE, PW, and wind represent a summary of atmospheric conditions. To check the role of driving variables in the MP72 process, we also consider relative humidity (RH) and air temperature $T$. Specifically, temperature averaged between 850 and $500 \mathrm{mb}$ (Tavg) is used to represent the "general air temperature," and the

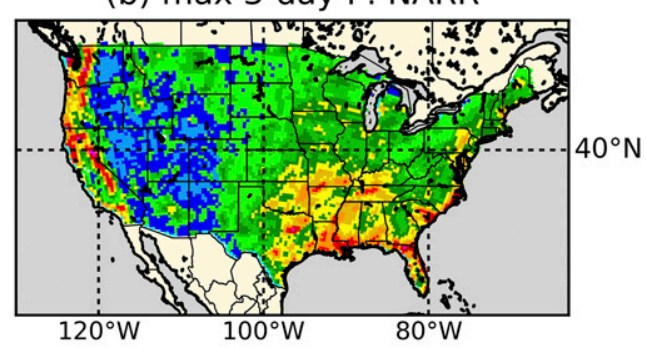

(d) correlation
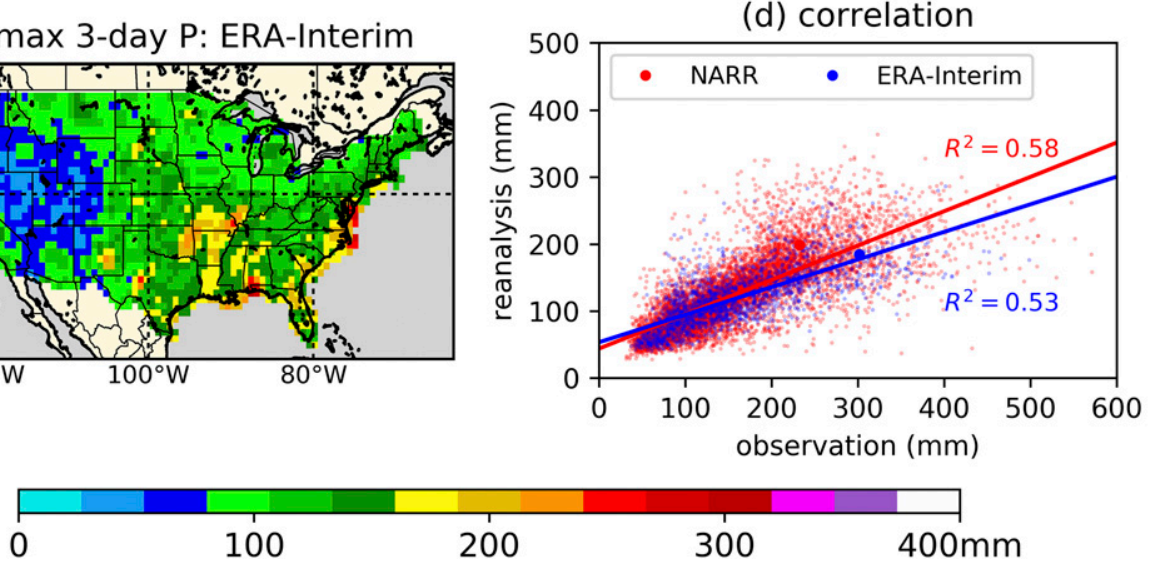

FIG. 1. Climatological max 3-day precipitation during 1979-2011 in (a) Livneh gridded observations, (b) NARR, and (c) ERA-Interim. (d) Regression between the observations and the two reanalysis datasets, where the $x$ axis is the Livneh data and the $y$ axis is the reanalysis data. For this plot, the Livneh data were conservatively regridded to the NARR/ERA-Interim model grids. 


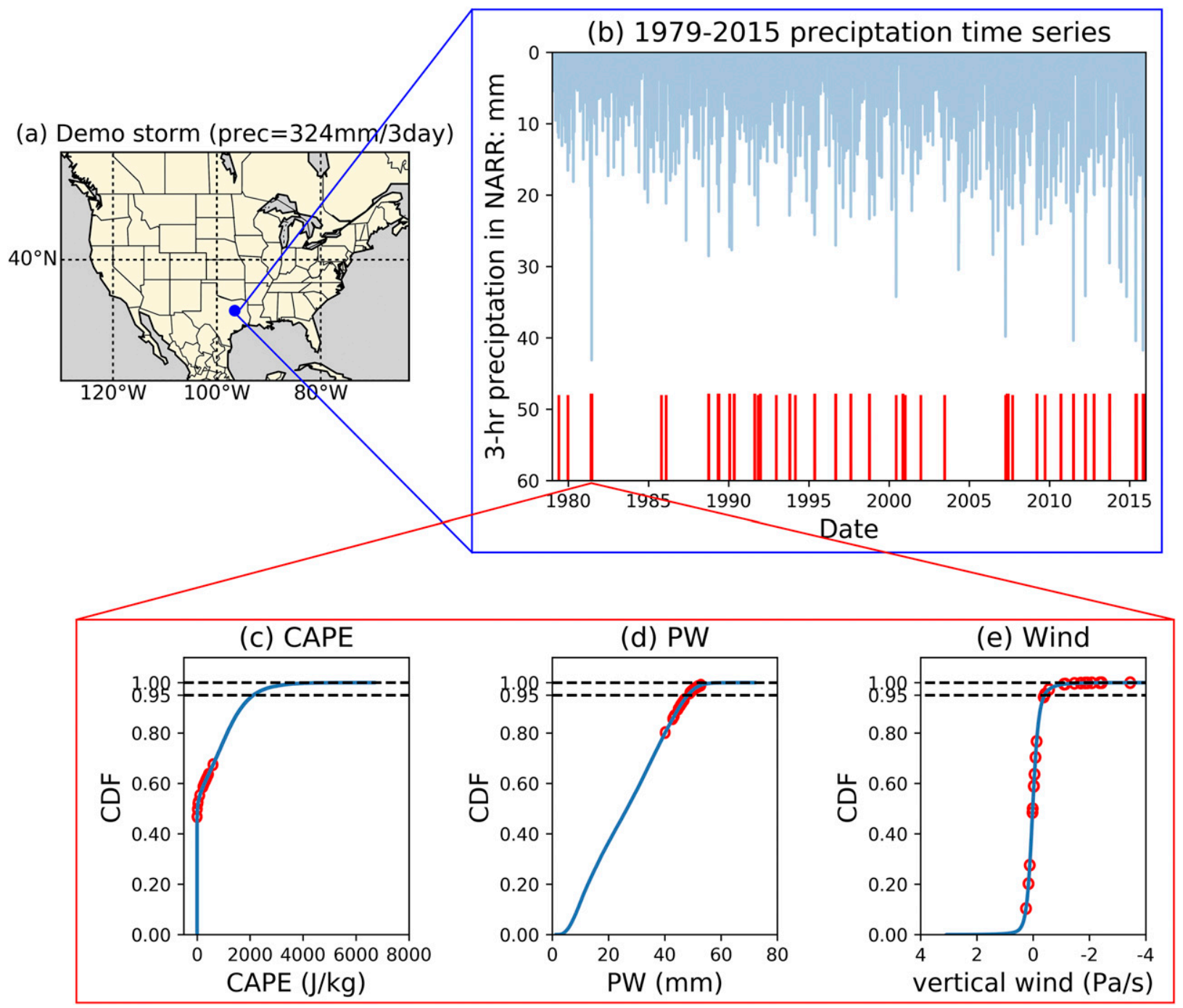

FIG. 2. (a),(b) Demonstration of frequency-based analysis. From a given grid, such as the blue point in (a), we can obtain the precipitation time series from the reanalysis (NARR or ERA-Interim) as shown in (b). Then we can identify the top fifty 72-h events with the greatest rainfall amount. These 50 periods are shown as red bars in (b). From the 36-yr reanalysis data, we can also obtain the climatology (CDF) of (c) CAPE, (d) PW, and (e) wind (blue curves). The red dots reflect the conditions of these factors in one 72-h storm duration. If we define $\mathrm{CDF}=95 \%$ (dashed lines) as the threshold of the extreme condition, it shows that in the 72-h duration, PW and vertical wind are persistently high, and we call them the controlling factors of this event. At one grid, if a factor controls most of the top 50 events, then it is defined as the dominant control of the extreme storms at this grid.

temperature difference between 850 and $500 \mathrm{mb}$ (Tdiff; $850-\mathrm{mb} T-500-\mathrm{mb} T$ ) is used to represent the vertical temperature gradient.

\section{c. Analysis approach}

For analysis of long-duration events (more than a day), one difficulty is to define a state for atmospheric conditions that is representative for the storm duration. Therefore, we use frequency analysis to check the extent to which the atmospheric variables are extreme. Figure 2 depicts the procedures, and we give a step-by-step description here. First, at each grid (e.g., the blue grid in Fig. 2a), we compute the 3-day cumulative precipitation time series from reanalysis data (NARR or ERA-Interim) and collect the top 50 most severe 3-day precipitation events at every model grid during 1979-2015 (Fig. 2b). At this grid, we also compute the cumulative distribution function (CDF) of factor $X$ (CAPE, PW, wind, RH, Tavg, or Tdiff) using 1979-2015 records, as shown by the blue lines in Figs. 2c-e. Then, for each of these 50 events, we overlay the values of $X$ in the MP72 duration on the CDF curves. From these 
combined plots we then infer whether this variable also reaches extreme conditions. For the example storm in Fig. 2, the analysis indicates that PW and wind stay persistently high, and these variables control the magnitude of this storm. Compared with the previous studies where only the peak rainfall hour (or the surrounding $12 \mathrm{~h}$ ) environmental conditions are checked (Loriaux et al. 2016; Mishra et al. 2012), we do not focus on a specific hour, but rather the entire 72 -h duration. This is expected to reduce the bias in the results that are caused by the time lag between the peak rainfall and extreme environmental conditions.

To quantify these environmental controls, we take the $\mathrm{CDF} \geq 95 \%$ (we will call this parameter $p_{1}$ hereafter) as the threshold of extreme conditions (the dashed lines in Figs. 2c-e). If factor $X$ stays extreme (i.e., $C D F \geq 95 \%$ ) for over $15 \%$ (parameter $p_{2}$ ) of the MP72 duration (i.e., $\geq 4$ snapshots for 3 -h data, or $\geq 2$ snapshots for 6-h data), we define this event as controlled by $X$. Our choice of $p_{1}=95 \%$ and $p_{2}=15 \%$ may appear somewhat arbitrary. However, our sensitivity tests (Fig. S1 in the online supplement) indicate that the difference in the results is marginal when the analysis is performed with $p_{1}$ between $90 \%$ and $99 \%$ and $p_{2}$ between $10 \%$ and $20 \%$. Besides, our goal here is not to quantify the specific physical trigger but rather to identify the one that is statistically most prevalent (or dominant) at a given geographic location. By comparing the percentage of the top 50 events that are controlled by each factor, we can define the dominant physical control as the one controlling most events. The above analyses are based on the full records during 1979-2015, and the year-round dominant controls can be derived. By applying the analysis at seasonal scale, that is, using only the records and climatology information in the given season, we also investigate the seasonal variability of these physical controls.

Following the same analysis framework but for precipitation of different durations (e.g., 1 or 2 days), we can also investigate the dominant control of these different precipitation events.

\section{d. Estimation of precipitation change based on the dominant meteorological factor}

The above analysis reveals how extreme precipitation at a given location is related to the meteorological conditions. If factor $X$ plays a dominant role, then it is reasonable to expect that extreme precipitation will exhibit a similar trend as factor $X$. Because of the different magnitudes and units of measurement for different factors, this approach can only give binary info (i.e., increase or decrease) in the precipitation trend.

\section{Results}

\section{a. Historical change in extreme 3-day precipitation}

Figure 3 shows the trend of extreme 3-day precipitation between 1948 and 2010, from gridded observation data (Livneh et al. 2013). This $1 / 16^{\circ}$ dataset is available from 1915, but because of limited raw gauge data availability before 1948, we only analyzed the data after 1948. To check the trend during 1948-2010, for each year the 20 -yr average return interval (ARI) value was computed using the 3-day precipitation data in this year. Then linear regression was applied to estimate the trend (Fig. 3a), and the Mann-Kendall test was applied to check the significance of these trends (Fig. 3b). Figure $3 \mathrm{~b}$ only renders the grids where the trends are statistically significant under the Mann-Kendall test $(\alpha=0.1)$. It shows high spatial variation in the extreme precipitation trends, with mainly the central United States showing more significant increasing trends. Extreme precipitation in the northwestern United States and the southeastern United States shows decreasing trends, but the trends in the southeastern United States are not significant.

Compared with changes in hourly and daily extreme precipitation found in previous studies (Prein et al. 2017; Kunkel et al. 2013a), Fig. 3 shows higher spatial heterogeneity. This suggests that the sensitivity of longduration (i.e., longer than 1 day) extreme events to the past global warming is not the same across the CONUS, and some of them may be sensitive to other climate variables.

To connect the changes in extreme precipitation to meteorological conditions, we also computed the 1979-2015 trends of the NARR meteorological factors (CAPE, PW, wind, RH, and temperature) using the same method (Fig. S2). A visual comparison suggests the precipitation change (Fig. 3a) pattern mostly resembles the vertical wind change (Fig. S2c). Previous studies indicate that although changes in extreme precipitation follow the Clausius-Clapeyron relation, it can be different when local moisture convergence (strong wind) takes place (Trenberth 1999; Trenberth et al. 2003). Thus, it is necessary to look into the relationship between extreme precipitation and individual factors.

\section{b. How is 3-day extreme precipitation related to atmospheric conditions?}

Figure 4 shows the percentage of the top 50 local extreme precipitation events that are related to extreme CAPE, PW, and vertical wind from the NARR data. Overall, vertical wind velocity has the greatest impact on extreme precipitation, and this is reasonable given 

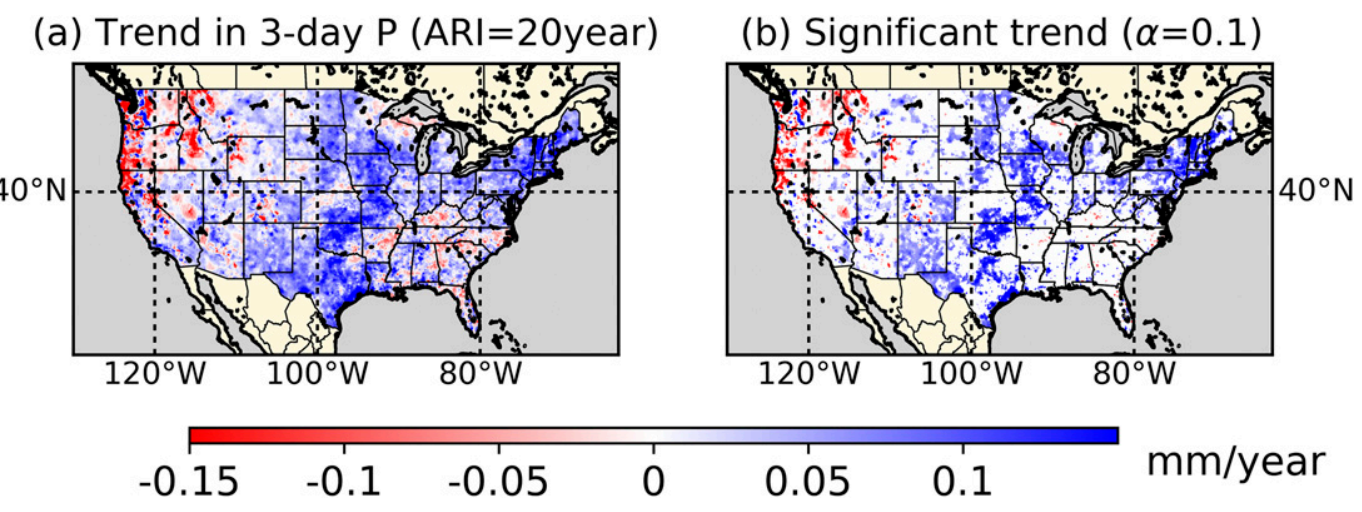

FIG. 3. Historical trends in extreme 3-day precipitation (taken as a 20-yr ARI) between 1948 and 2010. The trend is calculated using an annual 20-yr ARI 3-day precipitation series between 1948 and 2010 observations. (a) Trends from linear regression and (b) only the grids where the Mann-Kendall test shows a significant trend (at $\alpha=0.1$ level).

that vertical motion triggers moisture condensation. It is necessary to note the cause of the strong impact of vertical velocity on the West Coast and the southeastern United States is different, which feature atmospheric river systems and mesoscale convective systems (cyclones), respectively. Regarding this "absolute impact," both CAPE and PW have similar patterns: they are closely related to extreme precipitation in the central United States, but less so on the West Coast and in the southeastern United States. The southeast region experiences high CAPE year round (Fig. S3a), so it is not a particularly important factor in extreme precipitation occurrences. In the northwest region, most of the extreme precipitation events happen in wintertime, when the air is cold and stable. Also, these are mainly atmospheric river landfall events where abundant moisture is raised and then condenses along the coastal Cascade Range. Thus, CAPE does not play a key role there. The fact that extreme precipitation is more related to vertical wind velocity than PW is because vertical wind also implies large-scale horizontal convergence, which brings in moisture from the surrounding area in the precipitation process. This is in agreement with findings from previous studies that during extreme rainfall events, the consumed moisture is several times that of PW (Kunkel et al. 2013b).

Similarly, Figs. 4c-f show the impact of distinct meteorological factors from NARR. They are wind (Fig. 4c), RH (Fig. 4d), average temperature (Fig. 4e), and the temperature gradient (Fig. 4f). It is obvious that vertical wind and $\mathrm{RH}$ are the significant top two controls in general. Specifically, wind controls storms on the West Coast and in the southeastern United States, and $\mathrm{RH}$ controls the mountainous region in the western United States, as well as the Appalachian Mountains. The significant role of $\mathrm{RH}$ is because $\mathrm{RH}$ has a natural upper bound (of $100 \%$, or $\sim 105 \%$ in supersaturation situations), and in the extreme precipitation duration, it often stays at this upper bound persistently. PW is affected by two factors: Tavg (i.e., the maximum moisture holding capacity) and RH (how close the actual air moisture is to the maximum moisture holding capacity). Figure 4 indicates that Tavg is not a key factor in driving PW to an extreme condition in precipitation (Fig. 4b). Tavg and Tdiff have the greatest impact in the centralnorth United States, around the Great Lakes. Also, Tavg has a significant role in the southeast coastal regions and Florida.

\section{c. Year-round dominant controlling factor}

Based on Figs. 4 and 5, we can now compare the strengths of relationship with various factors and pick a single factor that controls most of the 50 events as the dominant control of extreme 3-day precipitation at that grid. Figure 5 shows the distribution of such year-round dominant controls. Figures $5 \mathrm{a}$ and $5 \mathrm{~b}$ paint the "competition" among general atmospheric conditions (atmospheric instability, moisture availability, and wind convergence). We can see that storms are mostly controlled by vertical wind (i.e., convergence) in general, though within the mountainous regions of the western United States they would also be dominated by CAPE or PW. Both NARR and ERA-Interim show similar patterns, except that ERA-Interim shows an expanded region that is dominated by CAPE. The CAPE/PW dominant regions are distributed in the southwestern United States, where the climate is dry and hot. Therefore, air tends to be dry and stable, requiring significant perturbation or abundant moisture influx before condensation can happen.

Figures $5 \mathrm{c}$ and $5 \mathrm{~d}$ show the dominant meteorological factor in these precipitation events. Given that it is 
(a) NARR: Storms controlled by CAPE

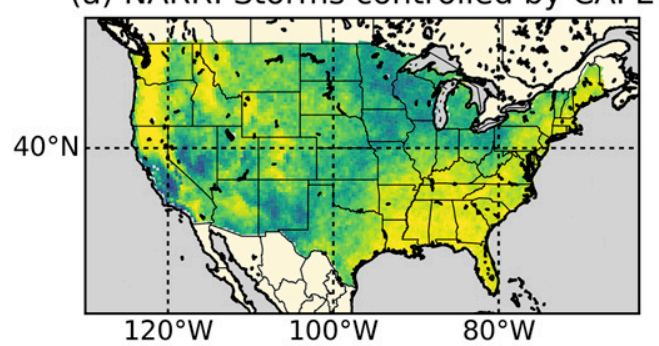

(c) NARR: Storms controlled by wind

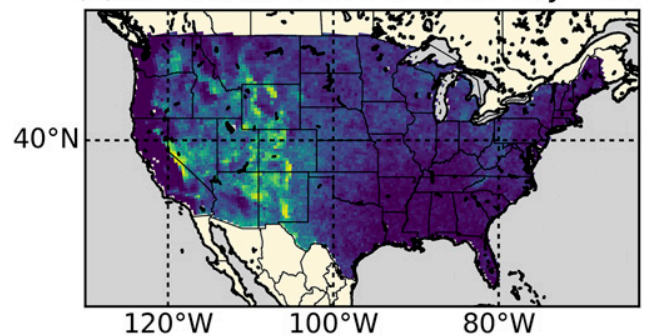

(e) NARR: Storms controlled by Tavg

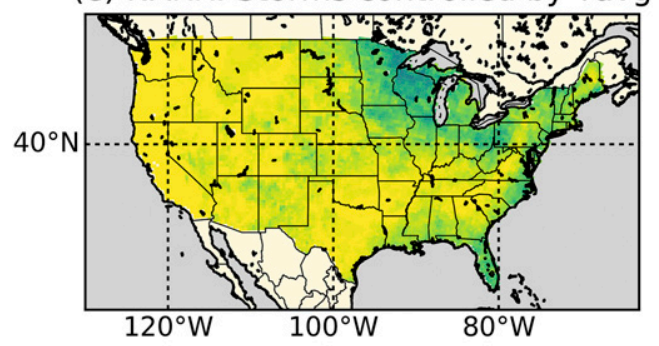

(b) NARR: Storms controlled by PW

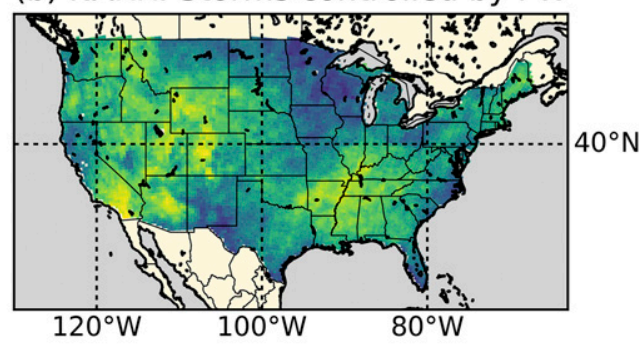

(d) NARR: Storms controlled by RH

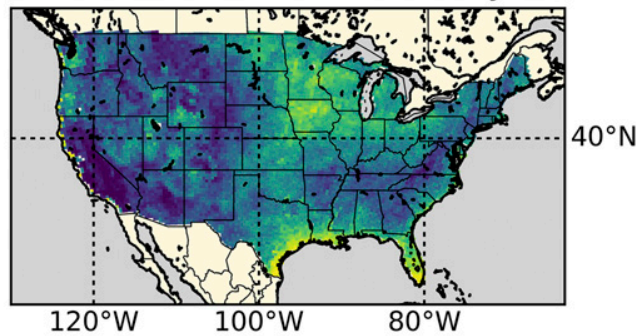

(f) NARR: Storms controlled by Tdiff

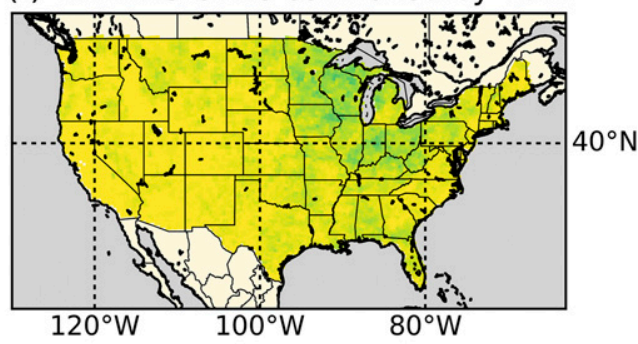

$60 \% \quad 80 \% \quad 100 \%$

FIG. 4. The percentage of top 50 extreme precipitation events that are related to extreme (a) CAPE, (b) PW, (c) wind, (d) RH, (e) Tavg, and (f) Tdiff during 1979-2015 from NARR. This reflects how many of the top 50 extreme 3-day rainfall events at a given grid are controlled by this meteorological factor.

easier for RH to reach its natural maximum (100\%) than PW, RH exhibits dominant roles in the western United States. Meanwhile, the seasonal variation (i.e., the range between winter and summer values) of RH is much smaller than other factors such as Tavg. Therefore, even for those extreme events occurring in winter, it would still be possible for $\mathrm{RH}$ to reach its annual maximum. For these reasons, we performed another evaluation excluding RH, and the results are illustrated in Figs. 5e and $5 \mathrm{f}$. It indicates that as $\mathrm{RH}$ is taken out from the analysis, wind becomes the single domainwide dominant factor. The domainwide dominance of wind can also be partially explained by the weak seasonal cycle of wind, compared to Tavg and Tdiff.

Though both NARR and ERA-Interim yield similar results, the major difference between the two is the contribution of wind. As seen in Fig. 5d, over the mountainous western United States, ERA-Interim gives fewer regions that are dominated by wind. This is likely due to the coarse horizontal resolution in the ERAInterim data, which makes it harder to elicit the finerscaled variation in wind speed as air flows over the mountainous regions. Such an impact from topography is also visible in Fig. 5d, where the Pacific Northwest region (upper-left region) in ERA-Interim shows continuous control under wind, while NARR successfully resolves the impact of the Cascade Range near the coast. Another difference is the description of mesoscale convection systems (such as cyclones) in both datasets. In the ERA-Interim product, the 75 -km horizontal grids cannot capture the spatial variability of cyclonic or tropical storm activities in the eastern United States, 
(a) NARR: (CAPE/PW/wind)

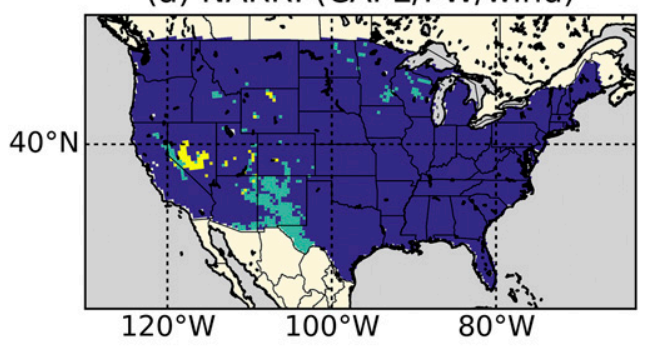

(b) ERA: (CAPE/PW/wind)

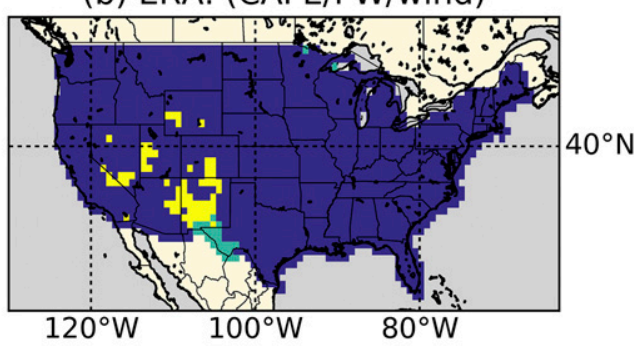

wind

(c) NARR: (wind/RH/Tavg/Tdiff)

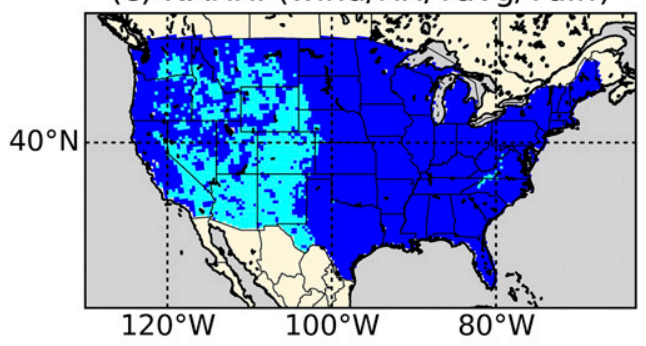

(d) ERA: (wind/RH/Tavg/Tdiff)

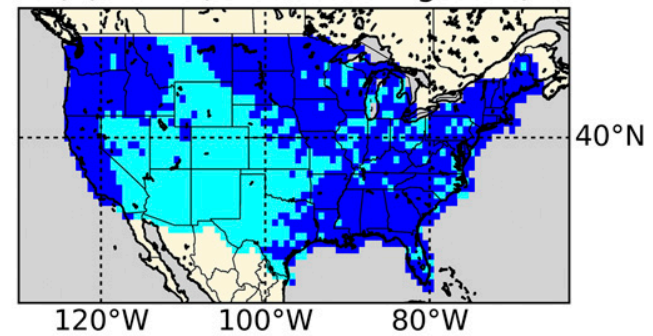

Tavg Tdiff

(f) ERA: (wind/Tavg/Tdiff)

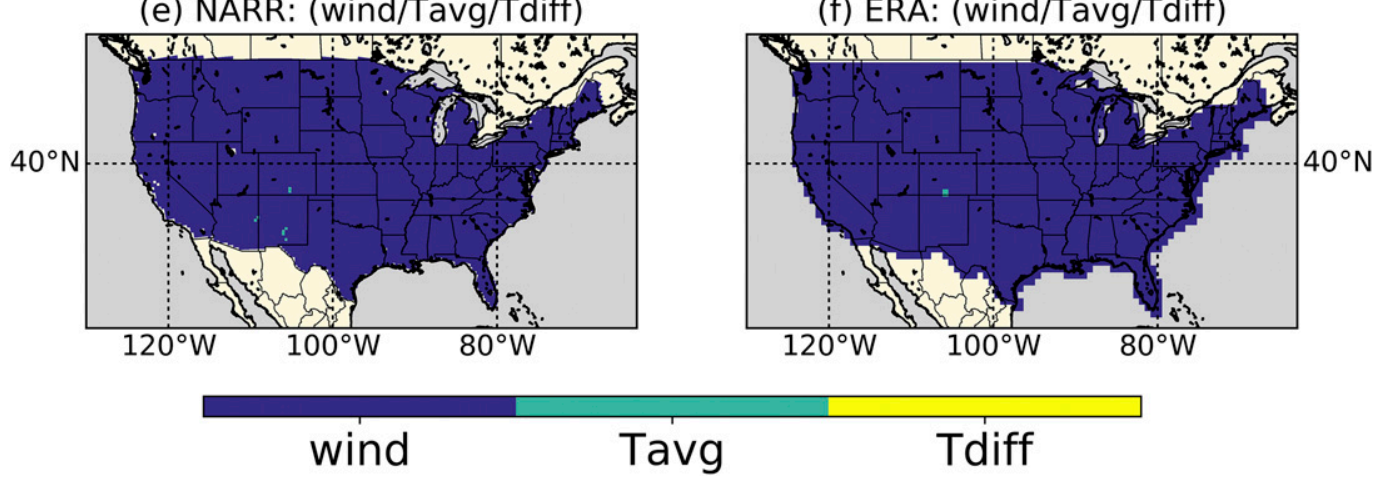

FIG. 5. Year-round dominant control over extreme precipitation across the CONUS for (left) NARR and (right) ERA-Interim for analyses using (a),(b) CAPE/PW/wind; (c),(d) wind/RH/Tavg/Tdiff; and (e),(f) wind/Tavg/Tdiff.

which contribute a considerable number of extreme precipitation events in this region.

\section{d. Seasonality of dominant controls}

Figure 6 shows the seasonal variation in the dominant controls from NARR. For comparison, ERA-Interim results are shown in Fig. S4. Both reanalysis datasets show highly similar patterns, and they resemble the year-round patterns to a good extent. This simplifies the implementation of the findings in this study and indicates that the dominant factors found here are stable. In the CAPE/PW/wind analysis, the southwestern United States is more related to PW, since it is dry there in summer, and moisture controls the initialization of precipitation. Also, the northern United States is controlled by CAPE along with wind in winter, as cold air is stable during winter. Regarding the wind/RH/Tavg/Tdiff analysis, the patterns are stable across seasons. This is because $\mathrm{RH}$ and wind, the two dominating factors, show less seasonal variability, and in all seasons it is easier for them to reach extreme values. 
(a) spring

(b) summer

(c) fall

(d) winter

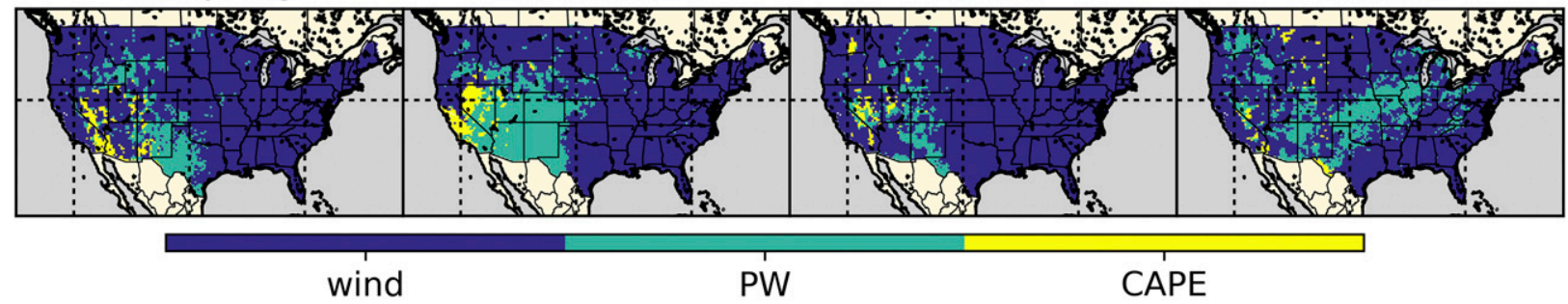

(e) spring

(f) summer

(g) fall

(h) winter

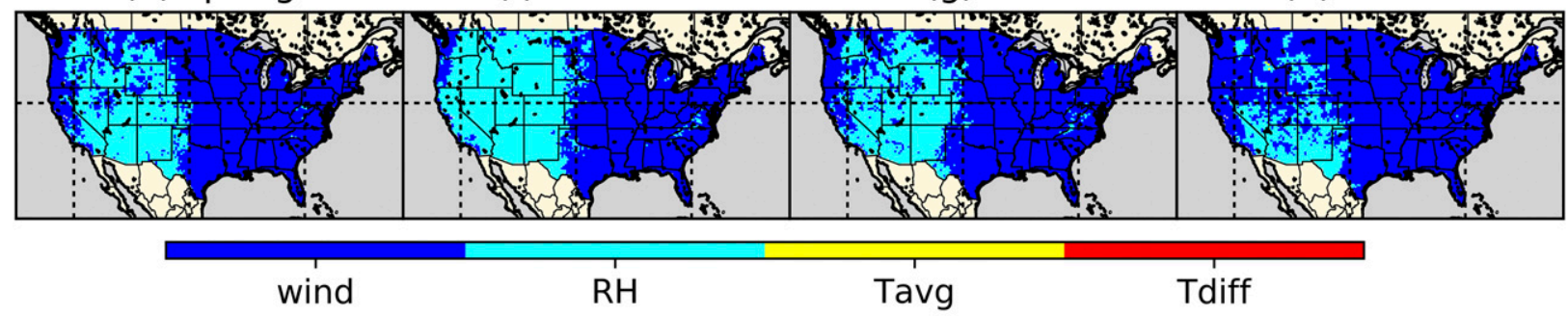

(i) spring

(j) summer

(k) fall

(I) winter

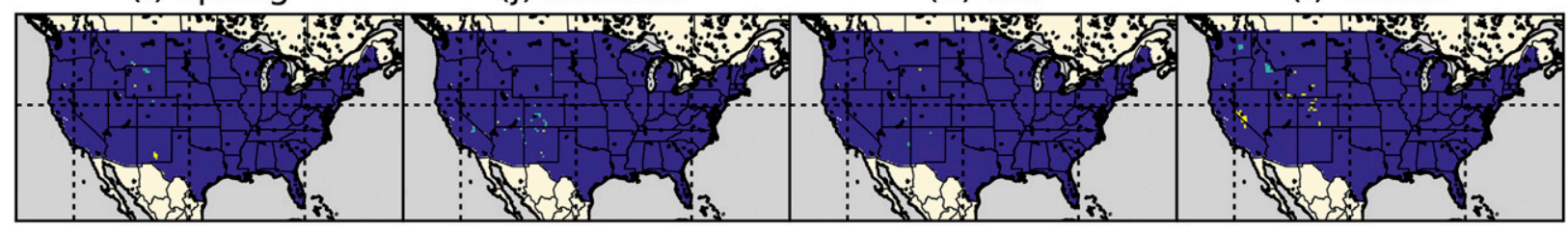

wind

Tavg

Tdiff

FIG. 6. Seasonal variations in the dominant controls from NARR: (a)-(d) the seasonality among wind/PW/CAPE, (e)-(h) the seasonal variation among wind/RH/Tavg/Tdiff, and (i)-(l) as in (e)-(h), but with RH removed from the analysis.

The only big difference between the two reanalysis results is during summer. NARR shows that the eastern United States is controlled by wind, while ERA-Interim shows this region is now controlled by RH. Again, this is likely due to ERA-Interim failing to capture cyclones or tropical storms in the eastern United States during summer when extreme precipitation is produced along with strong vertical winds. Therefore, the seasonality produced by NARR is more reliable.

\section{e. Inferring precipitation trends based on meteorological factors}

The difficulty of precipitation simulation has been widely recognized in climate modeling (IPCC 2001). Given the year-round dominant control map in Fig. 5a, it is possible to use the long-term trends of these factors in NARR to estimate the precipitation trends. In our analysis, if factor $X$ is the dominant control at a given grid, there is a positive relationship between extreme $X$ and extreme precipitation. Therefore, combining Fig. 5a with the trends of these factors during 1979-2015 (Fig. S2), we can estimate the binary trends (i.e., increase or decrease) of extreme precipitation; the results are shown in Fig. 7. As a validation, the trends derived from the Livneh dataset are shown in Fig. 7a. This is the same as Fig. 3a, but with exact values removed. Figure $7 \mathrm{~b}$ shows the estimation based on the trends of meteorological factors. The large-scale spatial patterns show a good match: the vast regions in the middle and eastern United States show increased precipitation; the northwestern and southeastern United States show decreased extreme precipitation. It is necessary to point out that Fig. $7 \mathrm{a}$ is derived from $1 / 16^{\circ}$ data, so it presents more variation at finer scales. Such a good match suggests that it is possible to estimate the extreme precipitation trend from the long-term trends of related meteorological factors (that are easier to simulate reliably).

\section{Discussion}

For the guidelines derived in this study to be ready to use in engineering practice, they need to be robust and include an estimate of uncertainty. Here, we check the 


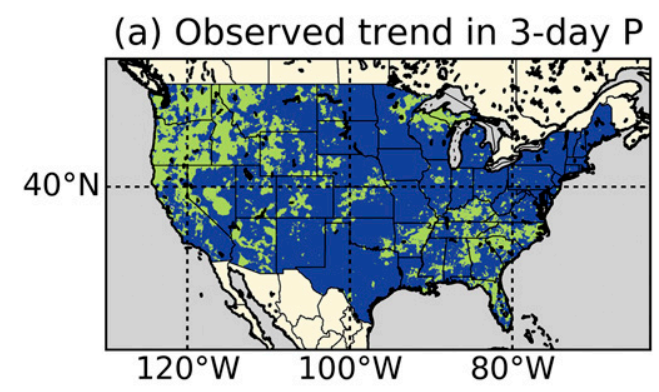

(b) Inferred trend in 3-day $P$

\section{decrease (-) increase (+)}

FIG. 7. The (a) observed and (b) inferred binary trend of extreme 3-day precipitation, where (a) is as in Fig. 3a, but without actual trend values. The inferred trend in (b) is based on the dominant control map (Fig. 5a) and the trend in CAPE, PW, and wind (Fig. S2). Details on the computation of this plot are in section 2.

robustness of our results (both in the results themselves and how they compare to the previous studies). Also, as the guidelines are derived from relatively coarse resolution data (as compared with those high-resolution simulations suggested by climate modeling communities), the internal uncertainty in the simulated meteorological factors and thus the derived results are also investigated.

\section{a. Robustness check}

We checked the robustness of our results in three ways:

1) We checked the generated maps (Figs. 4-6) using different thresholds. In the presented results, we used $p_{1}=95 \%$ and $p_{2}=15 \%$ (i.e., $\mathrm{CDF} \geq 95 \%$ and $15 \%$ of 72 -h duration) as thresholds. We perturbed $p_{1}$ between $90 \%$ and $99 \%$, and $p_{2}$ between $10 \%$ and $20 \%$ in the sensitivity experiments. The results (Fig. S1) are similar to Fig. 5a.

2) We conducted the analysis using NARR and ERA-Interim data individually. The ERA-Interim results are shown in Fig. 5 and Fig. S4. Despite the difference in horizontal grid size $(32 \mathrm{~km}$ and $75 \mathrm{~km})$, the derived control maps share very similar spatial patterns.

3) We conducted another analysis, focusing on 1- and 2-day extreme precipitation events. The derived maps of dominant atmospheric conditions (Fig. 8) resemble Fig. 5. Thus, the patterns we find here are robust for multiday extreme precipitation events.

\section{b. Spatial variations of physical controls}

Previous studies have checked the quantitative relationship between rainfall intensity and meteorological conditions (Lepore et al. 2015; Mishra et al. 2012;
Loriaux et al. 2016). Some of the studies regress the rainfall intensity $P$ to moisture availability $T_{d}$ and atmospheric instability (CAPE), and the results indicate that there is considerable variation in these regressions. For example, in the study of the United States east of the Rocky Mountains (approximately east of $105^{\circ} \mathrm{W}$; see Fig. S6), the regression coefficient between $P$ and $T_{d}$ varies between 0.04 and 0.06 in 100-yr return period extreme storms (Lepore et al. 2015). Specifically, this coefficient is higher in the northeastern United States (regions around the Great Lakes, "North" region in Fig. S6), and lower in the southeastern United States ("South" in Fig. S6). This is consistent with our results that PW is related to more extreme storms in the northeastern United States, while the relationship is weak in the southeastern United States (Fig. 4b). In terms of CAPE, the regression analysis indicates that $P$ is most sensitive to CAPE in the northeastern United States (regions around the Great Lakes, "North" in Fig. S6), and the sensitivity decreases as it moves from north to south. Such a gradient is also consistent with Fig. $4 \mathrm{a}$, where storms in the north are more related to CAPE, but less so in the southeast.

Compared to previous studies, we eliminated the biases introduced with different forms of regression. For example, some studies suggest that intensity of rainfall is positively related to $\sqrt{\mathrm{CAPE}}$ (North and Erukhimova 2009), while others tried to regress rainfall intensity to CAPE (Lepore et al. 2015). In our approach, we only focus on the percentiles of CAPE values, so the relationships derived (Fig. 4) are free from assuming different forms of regression. Our results also suggest that the roles of these physical controls exhibit significant spatial heterogeneity, and they may need to be considered at a local scale to achieve even more reliable results. 


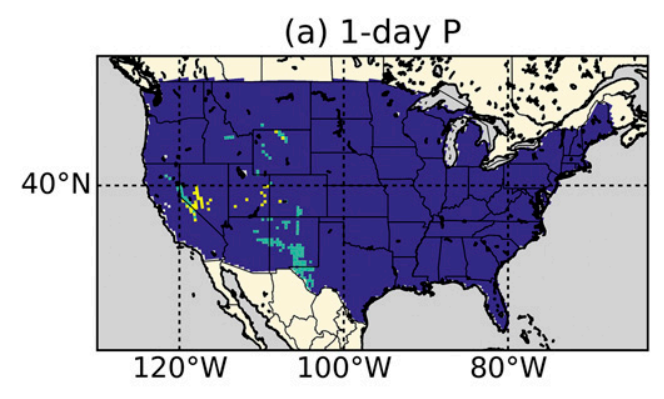

(b) 2-day $P$

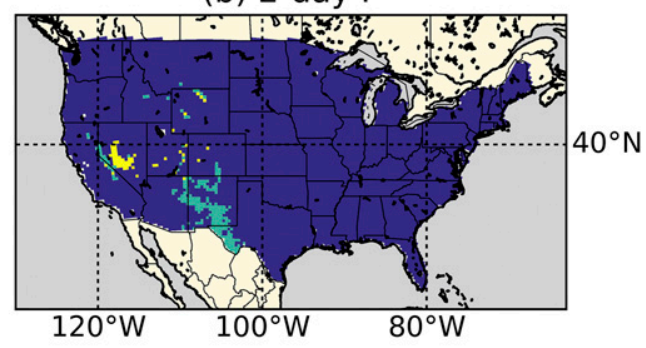

wind

(c) 1-day $P$
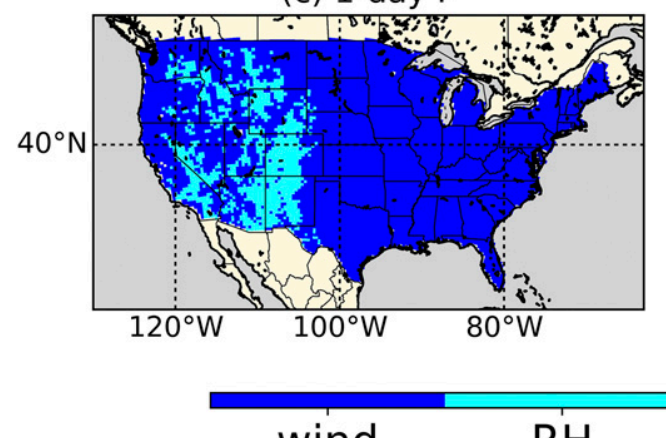
$\mathrm{RH}$

\section{PW}

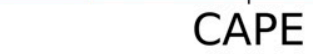

(d) 2-day $P$

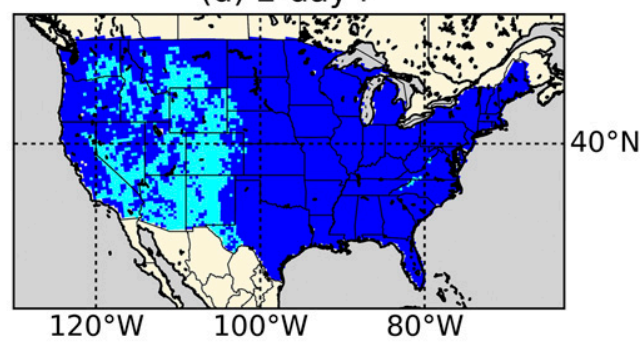

Tavg

\section{Tdiff}

FIG. 8. Dominant atmospheric conditions in extreme 1- and 2-day precipitation analysis for (a),(b) wind/PW/CAPE and (c),(d) wind/RH/Tavg/Tdiff.

\section{c. Uncertainty analysis}

While NARR is the highest-resolution reanalysis available over the CONUS, the largest uncertainty in this analysis still originates from its relatively coarse resolution. It is known that such coarse resolution cannot fully resolve some of the mesoscale convective systems and tropical/extratropical cyclones. Also, the presentation of topography would lead to biases in the simulated moisture flow from cold season extreme precipitation in mountain regions (Prein et al. 2013). To check the potential biases in our results, we performed the same analysis (but over only PW and 700-mb vertical velocity) over a 4-km WRF simulation across the CONUS during 2001-12 (Liu et al. 2017). As a reference, new maps based on 2001-12 NARR data were also computed and shown in Fig. 9. Figure 9a is the percentage of top 50 storms that are related to extreme PW, and Fig. $9 \mathrm{~b}$ is for vertical velocity. They are similar to Figs. $4 \mathrm{~b}$ and $4 \mathrm{c}$, but representative of the 2001-12 period. Figures $9 \mathrm{c}$ and $9 \mathrm{~d}$ are the results from WRF simulation. It shows that the PW pattern in the 4-km grid simulation is similar to the NARR result, so bias correction of the PW results is not necessary. For vertical wind, however, the WRF simulation indicates that over the western
United States, fewer storms are related to vertical velocity than that reflected in the NARR results. Therefore, bias correction is required.

Based on Eq. (3), we can correct the wind percentage map in Fig. $4 \mathrm{c}$ as

$$
\begin{aligned}
\mathrm{pct}_{\mathrm{NARR}, \mathrm{bc}}= & \mathrm{pct}_{\mathrm{NARR}, 1979-2015}+\mathrm{pct}_{\mathrm{WRF}, 2001-12} \\
& -\mathrm{pct}_{\mathrm{NARR}, 2001-12} .
\end{aligned}
$$

In Eq. (3), pct NARR,bc is the bias-corrected percentage, pct $_{\text {NARR,1979-2015 }}$ is the NARR percentage in Fig. 4c, pct $_{\mathrm{WRF}, 2001-12}$ is the percentage derived from WRF (Fig. 9d), and pct $_{\mathrm{NARR}, 2001-12}$ is the percentage in 2001-12 NARR data (Fig. 9b). Using the bias-corrected wind percentage map, we can generate a new dominant control map, as shown in Fig. 10. Figure 10a shows less dominant roles of vertical wind over the storms in the western United States (excluding the West Coast). This makes more sense, as the Pacific Ocean provides a moisture source for the extreme precipitation in this region. With the better presentation of the topographic impact in the model, moisture tends to be lifted and condensed as it travels above the Rocky Mountains. Therefore, it is critical to have enough moisture retained 
(a) NARR (2001-2012): PW

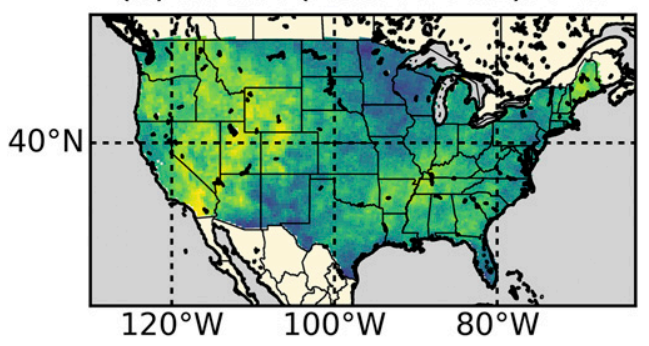

(c) WRF (2001-2012): PW

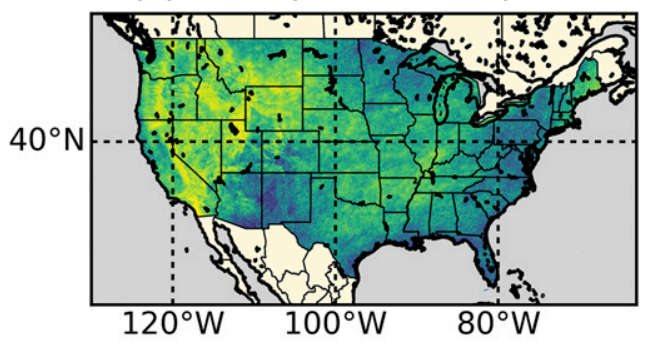

(b) NARR (2001-2012): wind

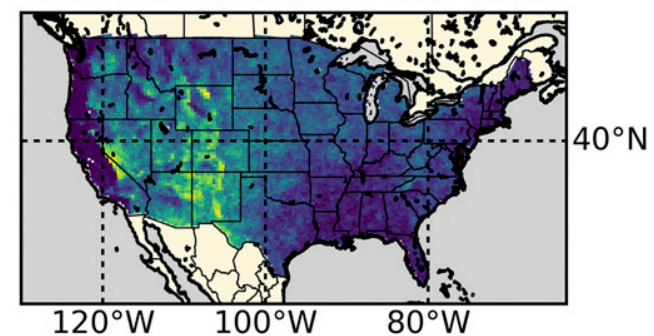

(d) WRF (2001-2012): wind

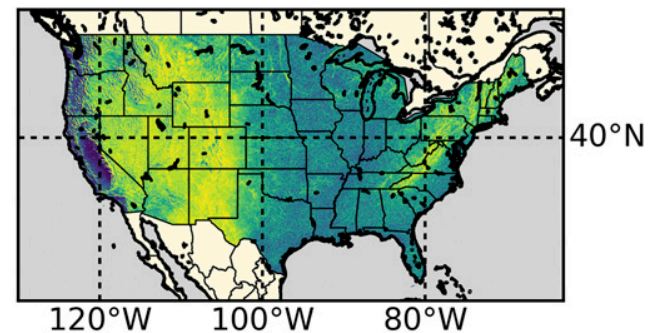

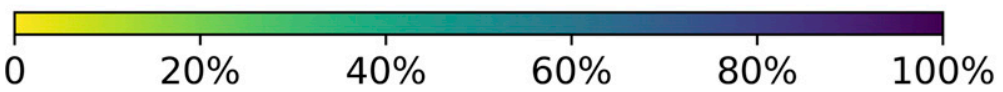

FIG. 9. Impact of reanalysis resolution on the analysis of (a) PW and (b) wind, both derived from 2001-12 NARR data. Analyses of (c) PW and (d) wind from a 4-km WRF simulation in the 2001-12 duration (using ERA-Interim data as initial and boundary conditions).

in the airflow for the heavy precipitation to happen in the western United States. The big patterns between Fig. 10b and Fig. 5c are similar, though the better description of the Appalachian Mountains now results in less wind control in this region.

\section{d. Model-based PMP estimation}

As mentioned earlier, the main motivation of our study is the recent advances in PMP estimation using numerical atmospheric models. Despite various efforts to investigate how to use models to maximize the extreme historical rainstorms to the PMP level (Ohara et al. 2011; Ishida et al. 2015; Tan 2010), there has been no general agreement reached so far within the community. Various maximization approaches have been applied to various storms, but the extent to which they maximize the storms differs greatly. Considering the spatial variation of the physical controls shown in Figs. 5 (a) NARR+WRF: (CAPE/PW/wind)

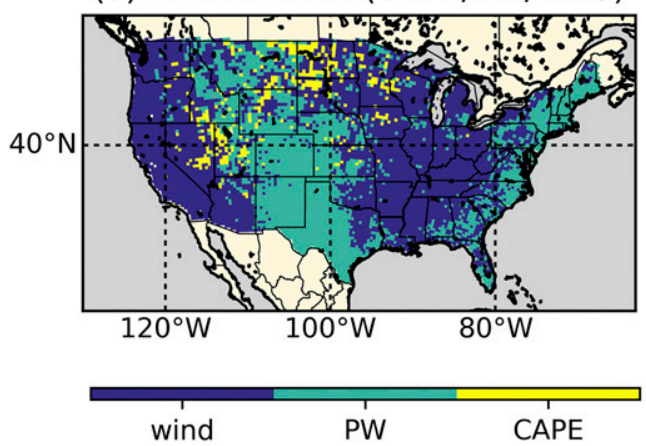

(b) NARR+WRF: (wind/RH/Tavg/Tdiff)

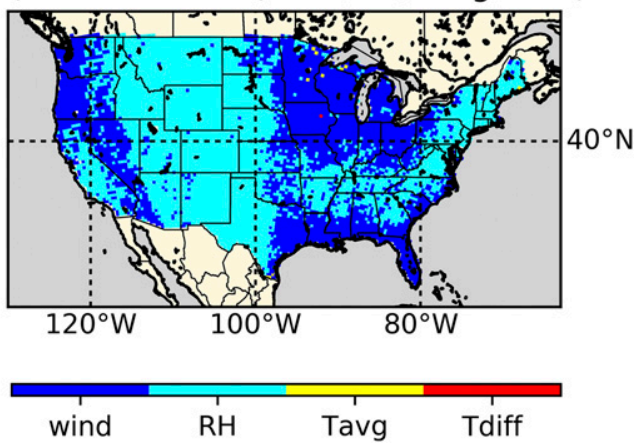

FIG. 10. Dominant meteorological conditions derived from NARR and a 4-km WRF simulation. Wind results (i.e., Fig. 4c) are corrected using a 4-km WRF simulation (2001-12), and the other percentage results are as obtained from the 1979-2015 NARR analysis (Fig. 4). Details on the correction of wind results are described in section 4c. 
and 7 , this is likely due to the different dominant controls on the storms at different locations. For example, Ohara et al. (2011) tested several methods over the 1997 January storm in central California (American River watershed) and found that the perturbation of the horizontal wind convergence produced a much larger "PMP storm" than increasing the relative humidity to $100 \%$. This result can be explained by Fig. 5a, where central and southern areas of California are mainly controlled by the vertical wind velocity. At the same time, Ohara et al. (2017) found that increasing RH to $100 \%$ sometimes leads to decreased precipitation. This can now also be explained by the dominant role of vertical wind (rather than $\mathrm{PW}$ ) at this location. At wind-control locations, the disturbance of wind speed would greatly change the rainfall magnitude, while at PW-control locations rainfall magnitude will change more under air moisture change. On the other hand, $\mathrm{RH}$ is the only considered driver that gets maximized in the model. This makes sense for the western United States (excluding the West Coast area) if we look at Figs. 6c and $6 \mathrm{~d}$, where RH dominates the western United States. However, RH has a physical upper bound (100\%), and it is often already $100 \%$ in the storm duration, so maximizing it cannot fully release the precipitation potential. This may also explain why the model-based PMP estimation using RH maximization tends to be lower than the value from NOAA's operational guideline Hydrometeorology Reports (HMRs; Tan 2010; Ohara et al. 2011). In HMRs, we maximize the precipitation using $\mathrm{PW}$, while RH is only a factor in PW. Therefore, it is important to determine the key control of the rainstorms over the study region and release this constraint in the model accordingly.

Based on our analysis, we suggest that RH should be the first factor to be maximized in model-based 3-day PMP estimation. Since RH has a natural limit of $100 \%$, setting RH to $100 \%$ does not necessarily amplify the storm to its upper bound. In this case, considering the second factor would be useful: the wind field is an important factor to consider in the model. By setting the wind field to its climatological maximum, precipitation would be amplified to a reasonably higher amount. Such numbers should make a safer and more physics-based PMP estimate. For a more detailed PMP design, it may be worthwhile to check the dominant controls at the seasonal (or even monthly) scale and finer-resolution regional climate simulations when available, and then configure the models accordingly.

In numerical models, the RH maximization can be achieved by setting the $\mathrm{RH}$ in the boundary condition to $100 \%$. This is the same as what has been explored in previous studies (Ohara et al. 2011; Ishida et al. 2015;
Tan 2010; Rastogi et al. 2017). Regarding the wind maximization, since mass balance always needs to be held, the following procedures are required:

1) For the 72-h storm duration, calculate the mean $700-\mathrm{mb}$ vertical wind speed over the desired watershed (as $\left.W_{\text {event }}\right)$.

2) Calculate the time series of $72-\mathrm{h}$ averaged $700-\mathrm{mb}$ vertical wind speed over the same watershed over a long term. Then the maximum value can be identified as the climatological maxima (as $W_{\max }$ ).

3) Compute the maximization ratio as $W_{\max } / W_{\text {event }}$.

4) When preparing the boundary data of the PMP simulation, multiply this maximization ratio to the whole 3D wind field (i.e., both vertical and horizontal winds) at all levels from reanalysis or climate model data to create the maximized wind fields.

In this study, we have provided data-driven rationale and guidance to engineers on what physical triggers would make the most justification in configuring a numerical model for estimating 3-day PMP. Based on similarities between Figs. 5 and 8, such guidance is also valid for 1- and 2-day PMP estimation. For PMP estimation of other different durations, the frequency-based analysis framework we introduced here can be used to identify the key controlling factors.

\section{Conclusions}

We used NARR and ERA-Interim to investigate the roles of general atmospheric conditions (instability, moisture availability, wind convergence) and atmospheric drivers (vertical wind, relative humidity, air temperature) in extreme rainstorm events. These relationships bring guidelines toward a physics-based PMP estimation framework. Our conclusions are as follows:

1) Extreme 3-day precipitation shows different trends across the CONUS. The central United States shows a significant increase during 1948-2010. The extreme precipitation in the western United States and part of the southeastern United States has a decreasing trend over time, although the decrease in the southeastern United States appears statistically nonsignificant. This can be explained by a strong relationship between extreme precipitation and vertical wind velocity across the United States.

2) Both reanalysis datasets show that extreme storms across much of the CONUS are closely related to vertical wind velocity. Storms in the southwestern United States are more related to moisture availability and atmospheric instability. 
3) From the perspective of atmospheric driving factors, relative humidity and vertical wind have a domainwide impact over extreme precipitation. The roles of these factors do not exhibit strong seasonality.

4) The engineering and water infrastructure community can use numerical models to physically estimate probable maximum precipitation after properly considering the existing major controls on extreme storms (i.e., RH and wind). This will help to provide more solid model-based PMP estimates.

For a physics-based PMP estimation framework across the CONUS, we find two flaws in the RH maximization methods that have been proposed by many in numerical modeling studies in the past: 1) RH may not be the major factor that mostly relates to extreme precipitation, especially in the eastern United States, where storm magnitudes are more related to the vertical wind velocity, and 2) because of its natural upper bound $(\sim 100 \%)$, it cannot maximize the extreme precipitation to its maximum extent. Here we suggest that besides the RH maximization, the vertical wind field maximization is also required for a reliable PMP estimation. By generating the map on the spatial distribution of dominant controls (Fig. 5), we also provide guidelines for the engineering community on which factor should be prioritized in different regions across the CONUS.

Our study opens the way for physics-based 3-day PMP estimation in the CONUS. At the same time, the frequency-based analysis framework of the study can also be applied to storm analysis at various durations and in other regions where high-resolution climate reconstruction (such as the most recent ERA-5 reanalysis product) is available. Our study provides a solid and evidence-based guideline to engineers for modernizing PMP estimation using numerical models and state-of-the-art atmospheric science.

Acknowledgments. The authors thank Professor Erkan Istanbulluoglu (University of Washington) and Dr. Ruby Leung (Pacific Northwest National Laboratory) for their contributions and constructive discussions in this study. All data, scripts, and analysis outputs are available upon request to the first author. All input data for the analysis were obtained from publicly available data repositories: NARR data were obtained from NCAR's Research Data Archive (http://rda.ucar.edu/datasets/ds608.0/); ERA-Interim data were obtained from NCAR's Research Data Archive (http://rda.ucar.edu/datasets/ds627.0/), except for precipitation data, which were obtained from the ECMWF web portal (http://apps.ecmwf.int/datasets/ data/interim-full-daily/levtype $=\mathrm{sfc} /$ ). The high-resolution WRF simulation data were obtained from NCAR's
Research Data Archive (https://rda.ucar.edu/datasets/ ds612.0/). The Livneh data were obtained at NOAA/ OAR/ESRL/PSD (https://www.esrl.noaa.gov/psd/data/ gridded/data.livneh.html).

\section{REFERENCES}

Abbs, D. J., 1999: A numerical modeling study to investigate the assumptions used in the calculation of probable maximum precipitation. Water Resour. Res., 35, 785-796, https://doi.org/ 10.1029/1998WR900013.

Brooks, H. E., J. W. Lee, and J. P. Craven, 2003: The spatial distribution of severe thunderstorm and tornado environments from global reanalysis data. Atmos. Res., 67-68, 73-94, https:// doi.org/10.1016/S0169-8095(03)00045-0.

Bukovsky, M. S., and D. J. Karoly, 2007: A brief evaluation of precipitation from the North American Regional Reanalysis. J. Hydrometeor., 8, 837-846, https://doi.org/10.1175/ JHM595.1.

Casagli, N., S. Dapporto, M. L. Ibsen, V. Tofani, and P. Vannocci, 2006: Analysis of the landslide triggering mechanism during the storm of 20th-21st November 2000, in Northern Tuscany. Landslides, 3, 13-21, https://doi.org/ 10.1007/s10346-005-0007-y.

Chang, H. I., A. Kumar, D. Niyogi, U. C. Mohanty, F. Chen, and J. Dudhia, 2009: The role of land surface processes on the mesoscale simulation of the July 26, 2005 heavy rain event over Mumbai, India. Global Planet. Change, 67, 87-103, https://doi.org/10.1016/j.gloplacha.2008.12.005.

Chen, X., and F. Hossain, 2016: Revisiting extreme storms of the past 100 years for future safety of large water management infrastructures. Earth's Future, 4, 306-322, https://doi.org/ 10.1002/2016EF000368.

Cong, X., G. Ni, S. Hui, F. Tian, and T. Zhang, 2006: Simulative analysis on storm flood in typical urban region of Beijing based on SWMM. Water Resour. Hydropower Eng., 37, 64-67.

Davies, L., C. Jakob, P. May, V. V. Kumar, and S. Xie, 2013: Relationships between the large-scale atmosphere and the small-scale convective state for Darwin, Australia. J. Geophys. Res. Atmos., 118, 11 534-11 545, https://doi.org/ 10.1002/jgrd.50645.

Dee, D. P., and Coauthors, 2011: The ERA-Interim reanalysis: Configuration and performance of the data assimilation system. Quart. J. Roy. Meteor. Soc., 137, 553-597, https://doi.org/ 10.1002/qj.828.

Ducrocq, V., and Coauthors, 2014: HyMeX-SOP1: The field campaign dedicated to heavy precipitation and flash flooding in the northwestern Mediterranean. Bull. Amer. Meteor. Soc., 95, 1083-1100, https://doi.org/10.1175/BAMS-D-12-00244.1.

Durkee, J. D., L. Campbell, K. Berry, D. Jordan, G. Goodrich, R. Mahmood, and S. Foster, 2012: A synoptic perspective of the record 1-2 May 2010 mid-south heavy precipitation event. Bull. Amer. Meteor. Soc., 93, 611-620, https://doi.org/10.1175/ BAMS-D-11-00076.1.

Evans, J. E., S. D. Mackey, J. F. Gottgens, and W. M. Gill, 2000: Lessons from a Dam failure. Ohio J. Sci., 100, 121-131, http:// hdl.handle.net/1811/23867.

Guan, B., N. P. Molotch, D. E. Waliser, E. J. Fetzer, and P. J. Neiman, 2010: Extreme snowfall events linked to atmospheric rivers and surface air temperature via satellite measurements. Geophys. Res. Lett., 37, L20401, https://doi.org/10.1029/ 2010 GL044696. 
Hand, W. H., N. I. Fox, and C. G. Collier, 2004: A study of twentieth-century extreme rainfall events in the United Kingdom with implications for forecasting. Meteor. Appl., 11, 15-31, https://doi.org/10.1017/S1350482703001117.

Hardwick Jones, R., S. Westra, and A. Sharma, 2010: Observed relationships between extreme sub-daily precipitation, surface temperature, and relative humidity. Geophys. Res. Lett., 37, L22805, https://doi.org/10.1029/2010GL045081.

Huschke, R. E., Ed., 1959: Glossary of Meteorology. Amer. Meteor. Soc., 638 pp.

IPCC, 2001: Climate Change 2001: The Scientific Basis. Cambridge University Press, 881 pp.

Ishida, K., M. L. Kavvas, S. Jang, Z. Q. Chen, N. Ohara, and M. L. Anderson, 2015: Physically based estimation of maximum precipitation over three watersheds in Northern California: Atmospheric boundary condition shifting. J. Hydrol. Eng., 20, https://doi.org/10.1061/(ASCE)HE.1943-5584.0001026.

Kharin, V. V., F. W. Zwiers, X. Zhang, and M. Wehner, 2013: Changes in temperature and precipitation extremes in the CMIP5 ensemble. Climatic Change, 119, 345-357, https:// doi.org/10.1007/s10584-013-0705-8.

Kumar, A., J. Dudhia, R. Rotunno, D. Niyogi, and U. C. Mohanty, 2008: Analysis of the 26 July 2005 heavy rain event over Mumbai, India using the Weather Research and Forecasting (WRF) Model. Quart. J. Roy. Meteor. Soc., 134, 1897-1910, https://doi.org/10.1002/qj.325.

Kunkel, K. E., and Coauthors, 2013a: Monitoring and understanding trends in extreme storms: State of knowledge. Bull. Amer. Meteor. Soc., 94, 499-514, https://doi.org/10.1175/ BAMS-D-11-00262.1.

, T. R. Karl, D. R. Easterling, K. Redmond, J. Young, X. Yin, and P. Hennon, 2013b: Probable maximum precipitation and climate change. Geophys. Res. Lett., 40, 1402-1408, https:// doi.org/10.1002/grl.50334.

Lepore, C., D. Veneziano, and A. Molini, 2015: Temperature and CAPE dependence of rainfall extremes in the eastern United States. Geophys. Res. Lett., 42, 74-83, https://doi.org/10.1002/ 2014 GL062247.

Liu, C., and Coauthors, 2017: Continental-scale convectionpermitting modeling of the current and future climate of North America. Climate Dyn., 49, 71-95, https://doi.org/ 10.1007/s00382-016-3327-9.

Livneh, B., E. A. Rosenberg, C. Lin, B. Nijssen, V. Mishra, K. M. Andreadis, E. P. Maurer, and D. P. Lettenmaier, 2013: A longterm hydrologically based dataset of land surface fluxes and states for the conterminous United States: Update and extensions. J. Climate, 26, 9384-9392, https://doi.org/10.1175/ JCLI-D-12-00508.1.

Loriaux, J. M., G. Lenderink, and A. P. Siebesma, 2016: Peak precipitation intensity in relation to atmospheric conditions and large-scale forcing at midlatitudes. J. Geophys. Res. Atmos., 121, 5471-5487, https://doi.org/10.1002/2015JD024274.

Markowski, P. M., J. M. Straka, and E. N. Rasmussen, 2002: Direct surface thermodynamic observations within the rearflank downdrafts of nontornadic and tornadic supercells. Mon. Wea. Rev., 130, 1692-1721, https://doi.org/10.1175/ 1520-0493(2002)130<1692:DSTOWT>2.0.CO;2.

Mesinger, F., and Coauthors, 2006: North American Regional Reanalysis. Bull. Amer. Meteor. Soc., 87, 343-360, https:// doi.org/10.1175/BAMS-87-3-343.

Min, S.-K., X. Zhang, F. W. Zwiers, and G. C. Hegerl, 2011: Human contribution to more-intense precipitation extremes. Nature, 470, 378-381, https://doi.org/10.1038/nature09763.
Mishra, V., J. M. Wallace, and D. P. Lettenmaier, 2012: Relationship between hourly extreme precipitation and local air temperature in the United States. Geophys. Res. Lett., 39, L16403, https://doi.org/10.1029/2012GL052790.

Moore, B. J., P. J. Neiman, F. M. Ralph, and F. E. Barthold, 2012: Physical processes associated with heavy flooding rainfall in Nashville, Tennessee, and vicinity during 1-2 May 2010: The role of an atmospheric river and mesoscale convective systems. Mon. Wea. Rev., 140, 358-378, https://doi.org/10.1175/ MWR-D-11-00126.1.

Neiman, P. J., L. J. Schick, F. M. Ralph, M. Hughes, and G. A. Wick, 2011: Flooding in western Washington: The connection to atmospheric rivers. J. Hydrometeor., 12, 1337-1358, https:// doi.org/10.1175/2011JHM1358.1.

Nigam, S., and A. Ruiz-Barradas, 2006: Seasonal hydroclimate variability over North America in global and regional reanalyses and AMIP simulations: Varied representation J. Climate, 19, 815-837, https://doi.org/10.1175/JCLI3635.1.

North, G. R., and T. L. Erukhimova, 2009: Atmospheric Thermodynamics: Elementary Physics and Chemistry. Cambridge University Press, $280 \mathrm{pp}$.

Ohara, N., M. Kavvas, S. Kure, Z. Chen, and S. Jang, 2011: Physically based estimation of maximum precipitation over American River watershed, California. J. Hydrol. Eng., 16, 351-361, https://doi.org/10.1061/(ASCE)HE. 1943-5584.0000324.

$\longrightarrow,-$, M. L. Anderson, Z. Q. Chen, and K. Ishida, 2017: Characterization of extreme storm events using a numerical modelbased precipitation maximization procedure in the Feather, Yuba, and American River watersheds in California. J. Hydrometeor., 18, 1413-1423, https://doi.org/10.1175/JHM-D-15-0232.1.

Pfahl, S., and H. Wernli, 2012: Quantifying the relevance of cyclones for precipitation extremes. J. Climate, 25, 6770-6780, https://doi.org/10.1175/JCLI-D-11-00705.1.

Prein, A. F., G. J. Holland, R. M. Rasmussen, J. Done, K. Ikeda, M. P. Clark, and C. H. Liu, 2013: Importance of regional climate model grid spacing for the simulation of heavy precipitation in the Colorado headwaters. J. Climate, 26, 4848 4857, https://doi.org/10.1175/JCLI-D-12-00727.1.

- , R. M. Rasmussen, K. Ikeda, C. Liu, M. P. Clark, and G. J. Holland, 2017: The future intensification of hourly precipitation extremes. Nat. Climate Change, 7, 48-52, https:// doi.org/10.1038/nclimate3168.

Rama Rao, Y. V., H. R. Hatwar, A. K. Salah, and Y. Sudhakar, 2007: An experiment using the high resolution Eta and WRF models to forecast heavy precipitation over India. Pure Appl. Geophys., 164, 1593-1615, https://doi.org/10.1007/s00024-007-0244-1.

Rastogi, D., and Coauthors, 2017: Effects of climate change on probable maximum precipitation: A sensitivity study over the Alabama-Coosa-Tallapoosa River basin. J. Geophys. Res. Atmos., 122, 4808-4828, https://doi.org/10.1002/ 2016JD026001.

Schreiner, L. C., and J. T. Riedel, 1978: Probable maximum precipitation estimates, United States east of the 105 th meridian. NOAA Hydrometeorological Rep. 51, 87 pp., http://www.nws. noaa.gov/oh/hdsc/PMP_documents/HMR51.pdf.

Seneviratne, S. I., M. G. Donat, B. Mueller, and L. V. Alexander, 2014: No pause in the increase of hot temperature extremes. Nat. Climate Change, 4, 161-163, https://doi.org/10.1038/nclimate2145.

Stratz, S. A., and F. Hossain, 2014: Probable maximum precipitation in a changing climate: Implications for dam design. J. Hydrol. Eng., 19, 06014006, https://doi.org/10.1061/ (ASCE)HE.1943-5584.0001021. 
Tan, E., 2010: Development of a methodology for probable maximum precipitation estimation over the American River watershed using the WRF Model. Ph.D. thesis, University of California, Davis, $194 \mathrm{pp}$.

Trenberth, K. E., 1999: Conceptual framework for changes of extremes of the hydrological cycle with climate change. Weather and Climate Extremes: Changes, Variations and a Perspective from the Insurance Industry, T. R. Karl, N. Nicholls, and A. Ghazi, Eds., Springer, 327-339.

, A. Dai, R. M. Rasmussen, and D. B. Parsons, 2003: The changing character of precipitation. Bull. Amer. Meteor. Soc. 84, 1205-1217, https://doi.org/10.1175/BAMS-84-9-1205.
Vaidya, S. S., and J. R. Kulkarni, 2007: Simulation of heavy precipitation over Santacruz, Mumbai on 26 July 2005, using mesoscale model. Meteor. Atmos. Phys., 98, 55-66, https:// doi.org/10.1007/s00703-006-0233-4.

Wang, J., Y. Han, M. L. Stein, V. R. Kotamarthi, and W. K. Huang, 2016: Evaluation of dynamically downscaled extreme temperature using a spatially-aggregated generalized extreme value (GEV) model. Climate Dyn., 47, 2833-2849, https:// doi.org/10.1007/s00382-016-3000-3.

World Meteorological Organization, 1986: Manual for estimation of probable maximum precipitation. Operational Hydrology Rep. 1, 2nd ed. WMO Publ. 332, 291 pp. 